\title{
INTERAÇÃO TRABALHO E FAMÍLIA: O ENRIQUECIMENTO COMO IMPLICAÇÃO DA ACUMULAÇÃO DE PAPÉIS
}

\author{
WORK-FAMILY ENRICHMENT: THE POSITIVE SIDE OF ROLES OF \\ ACCUMULATION
}

\section{Kadma Maia}

Mestre pela Universidade Federal do Rio Grande do Norte, UFRN, Brasil

Secretária Executiva pela Universidade Federal do Rio Grande do Norte, UFRN, Brasil

E-mail: kadmamaia@hotmail.com

\section{Jomaria Matta Alloufa}

Doutora pela Université de Paris X, Nanterre, Paris X, França

Professora pela Universidade Federal do Rio Grande do Norte, UFRN, Brasil

E-mail: jalloufa@yahoo.com.br

\section{Richard Medeiros de Araújo}

Doutor pela Universidade Federal do Rio Grande do Norte, UFRN, Brasil Professor pela Centro Universitário FACEX - UNIFACEX, UNIFACEX, Brasil E-mail: richardmaraujo@uol.com.br . 


\title{
INTERAÇÃO TRABALHO E FAMÍLIA: O ENRIQUECIMENTO COMO IMPLICAÇÃO DA ACUMULAÇÃO DE PAPÉIS
}

\section{RESUMO}

Este artigo visa compreender como a interação trabalho-família pode promover o enriquecimento nos papéis desenvolvidos por Secretários Executivos de uma Universidade Pública. A abordagem de análise utilizada foi a pesquisa qualitativa e a técnica de coleta de dados empregada a entrevista semiestruturada, aplicada a vinte secretários executivos, servidores da Instituição em estudo. Para a compreensão e interpretação dos dados, utilizou-se a técnica de análise de conteúdo. Os resultados das análises identificaram a existência de enriquecimento nessa interação. A oportunidade de agregar conhecimentos foi a mais citada como elemento enriquecedor do trabalho, e os valores da família como elemento enriquecedor da família. $O$ apoio e a experiência emergiram como fenômenos de enriquecimento comuns aos dois domínios. No que se referem às implicações do enriquecimento resultante da interação trabalho-família, as mais percebidas pelos entrevistados foram: aumento de conhecimentos e habilidades, benefícios materiais e psicológicos, melhoria da qualidade de vida e realização pessoal e profissional. Conclui-se que não se deve enfatizar o lado negativo da interação trabalho-família se há recursos favoráveis ao enriquecimento dessa relação. Valorizar o lado positivo, buscando o equilíbrio entre as demandas do trabalho e da família, é relevante, visto que a participação dos Secretários nos papéis familiar e profissional revelou-se uma dinâmica real, necessária e desafiadora, que pode levá-los ao enriquecimento.

Palavras-chave: Família. Trabalho. Enriquecimento trabalho-família.

\section{WORK-FAMILY ENRICHMENT: THE POSITIVE SIDE OF ROLES OF ACCUMULATION}

\begin{abstract}
This article aims at understand up how the interaction can promote work-family enrichment in the roles developed by the Executive Secretaries of a public university. The approach used was the qualitative analysis research and data collection technique employed a semi-structured interview, applied to twenty executive secretaries, employed at the public universities. For the data interpretation, we used the technique of content analysis. The analytical results identified the existence of enrichment in this interaction. The learning opportunity to was mentioned as one of the most enriching element of the work, besides the family values as family enriching element. The family support and experience emerged as enrichment phenomena common to both domains. Regarding the implications of work-family interaction, the most perceived implications by respondents were: increased knowledge and skills, material and psychological benefits, improved quality of life and personal and professional fulfillment. The conclusion is that one should not emphasize the negative side of the work-family interaction if there are favorable resources to enrich this relationship. One should also value the positive side of the interaction to seek a balance between the demands of work and the ones of family is equally important, since the participation of Secretaries in family and work roles proved to be necessary and challenging and it can provide enrichment to the executive secretary roles in their work place.
\end{abstract}

Keywords: Family. Work. Enrichment work and family. 


\section{INTRODUÇÃO}

As transformações no âmbito do trabalho e da família vêm sendo cada vez mais evidenciadas nas últimas décadas. Mudanças nos padrões, demandas e relações de trabalho, como também no perfil e na diversidade de estruturas familiares, entre outras, têm modificado significativamente a relação entre essas duas esferas da vida humana e despertado o interesse de pesquisadores por estudos na temática.

As investigações acerca da interação trabalho-família inicialmente foram focadas na perspectiva de conflito, isto é, no lado negativo dessa relação - embora o conflito tenha também o seu lado positivo que possibilita o desenvolvimento da maturidade e contribui para o fortalecimento da relação quando assume uma orientação focada na aprendizagem - e até hoje a maioria dessas investigações tem se concentrado nessa perspectiva. Em seguida surgem abordagens voltadas para a relevância do equilíbrio na relação e, posteriormente, emerge o interesse por estudos voltados para a facilitação, enriquecimento, que captura o lado positivo da interação desses domínios, isto é, a possibilidade de sinergia entre eles.

Esse lado positivo do trabalho tem sido visto como um meio de dar sentido à vida, de satisfação das necessidades pessoais, profissionais e familiares; um fator que impulsiona o crescimento e o desenvolvimento do ser humano. Nessa perspectiva, as experiências e recursos do trabalho podem contribuir para a melhoria da família, assim como, experiências e recursos da família podem contribuir para a melhoria no trabalho, de modo que o entendimento dos benefícios resultantes dessa relação é importante para todos os envolvidos. Nesse sentido, este trabalho objetivou compreender como a interação trabalho-família pode promover o enriquecimento nos papéis desenvolvidos pelo profissional de Secretário Executivo de uma Instituição Federal de Ensino Superior.

No Brasil, a profissão foi regulamentada pela lei 7.377 de 30-9-1985 e complementada pela lei 9.261 de 11-1-1996. Conforme a referida legislação, Secretário Executivo é o profissional diplomado no país por curso superior de secretariado, reconhecido na forma de lei, ou diplomado no exterior por curso de secretariado, cujo diploma seja revalidado no Brasil; o portador de qualquer diploma de nível superior que, na data da vigência da lei, houver comprovado, por meio de declarações de empregadores, o exercício efetivo de atividades que constem das atribuições mencionadas no Art. $4^{\circ}$ da lei, por um período mínimo de trinta e seis meses (Federação Nacional das Secretárias e Secretários, 1996).

O Secretário Executivo atua como assessor e gestor nas organizações, contribuindo com o administrador profissional no exercício da gestão, utilizando-se de conhecimentos, competências, responsabilidades, criatividade e discrição. Conforme a Classificação Brasileira de Ocupações (CBO), esse profissional encontra-se classificado no Grande Grupo 2 (GG2), que prevê uma formação com múltiplas competências, habilidades e elevado nível intelectual (Brasil, 1977).

A escolha pelo estudo junto a essa categoria profissional se deu em virtude da relevância da sua atuação em instituições públicas de ensino superior e pelo seu enquadramento no referido grupo, o qual lhe confere um novo perfil de atuação como assessor, gestor e consultor, exigindo-lhe mais tempo e dedicação no exercício da profissão. Conforme Sieber (1974), o envolvimento em 
múltiplos papéis pode ser benéfico à medida que expande a atenção do indivíduo e supera custos associados à participação de múltiplas funções.

Conforme o exposto, considerando que família e trabalho são grupos sociais importantes na vida e na formação do indivíduo, esta pesquisa buscou responder como a interação trabalho-família pode promover o enriquecimento nos papéis desenvolvidos pelo profissional de Secretário Executivo?

\section{INTERAÇÃO TRABALHO-FAMÍLIA E O ENRIQUECIMENTO}

Para Silva (2007) a análise da interação entre a vida profissional e familiar tem sofrido alterações ao longo do tempo. Inicialmente, os domínios do trabalho e da família eram vistos separadamente, ou seja, independentes e sem nenhuma relação. Contudo, mais recentemente, tem-se assistido a um crescente interesse na relação de interdependência dessas duas esferas. O desafio é a análise dos processos relativos à ligação entre esses domínios e os efeitos que cada um pode ter no outro e no indivíduo.

Conforme Edwards (2001), após a segunda guerra mundial, surge o interesse por estudos acerca das relações entre os papéis profissional e familiar. Esse interesse por pesquisas voltadas para os ambientes concorrentes do trabalho e da família se deu, em grande parte, a partir do aumento do número de mulheres que passaram a aliar a maternidade ao emprego remunerado, isto é, conciliar o seu papel familiar ao papel profissional.

A presença cada vez mais expressiva de mulheres no mercado de trabalho, nas últimas décadas, tem modificado o funcionamento da esfera familiar. As oportunidades de emprego para as mulheres, atreladas às demandas financeiras da família levaram ambos os atores do casal a contribuírem para obtenção da saúde financeira da família. Ou seja, famílias que tinham o elemento masculino como o único provedor do lar e o feminino com o papel de manutenção do lar passaram a dar lugar a famílias de duplo emprego, ou seja, que tinham um e outro sujeitos trabalhando fora de casa. (Edwards, 2001)

Na família, a renda é reunida para organizar um orçamento comum que possa satisfazer as necessidades de cada membro. Basicamente, a renda adquirida pela família é o que define suas possibilidades de aquisição de bens e serviços (Instituto Brasileiro de Geografia e Estatística, 2010). Essas argumentações revelam a importância do trabalho para as pessoas e para as famílias.

A hipótese da expansão ou aumento de recursos defende que a participação em múltiplos papéis pode proporcionar ao indivíduo recursos como, por exemplo, o desenvolvimento de novas competências e habilidades, e maior apoio social. O que provavelmente não se obteria se estivesse limitado ao desempenho de um único papel (Sieber, 1974).

Na visão de Hill (2007), a literatura conceitua a relação positiva recíproca trabalho-família utilizando quatro termos diferentes: a) spillover positivo trabalho-família; b) facilitação trabalhofamília c) enriquecimento trabalho-família e d) aprimoramento trabalho-família. Esses processos positivos têm sido associados a experiências individualizadas de compatibilidade trabalho-família, ajuste trabalho-família, equilíbrio e integração trabalho-família, que é caracterizada pela fusão e mistura de vários aspectos dessas esferas. Estes estudos têm contribuído para identificar aspectos da vida profissional que levam a resultados positivos na vida familiar, como também aspectos da vida 
familiar que levam a resultados positivos na vida profissional.

Segundo Grzywacz \& Marks (2000), a facilitação tem igualmente sido referida como enriquecimento. Em oposição à perspectiva do conflito, a teoria do enriquecimento de papel propõe que a participação em múltiplos papéis oferece aos sujeitos um grande número de oportunidades e recursos, os quais podem ser utilizados para promover o crescimento e um melhor funcionamento de um domínio entre outros da vida.

Para Sieber (1974) o enriquecimento sugere que o envolvimento em múltiplos papéis pode ser benéfico, à medida que expande a atenção do indivíduo e que a energia gerada por essa participação supera o estresse e outros custos associados a múltiplas funções. Nessa perspectiva de enriquecimento, as experiências de qualquer papel geram recursos que podem ser proveitosamente utilizados em outro, aumentando assim a qualidade de vida (Greenhaus \& Powell, 2006).

Ocorre facilitação entre papéis quando, a participação em um (por exemplo, no trabalho) torna-se melhor ou mais fácil em virtude da participação em outro (por exemplo, na família). Sendo assim, a facilitação trabalho-família (FTF) acontece quando o envolvimento de um indivíduo no trabalho resulta em aptidões, comportamentos ou humor positivo, que influenciam positivamente a vida familiar. Já a facilitação família-trabalho (FFT) sucede quando o envolvimento de um indivíduo na família resulta em suporte, humor positivo ou em sentimento de realização que ajuda trabalhar melhor e ter mais energia e confiança no trabalho (Wayne, Musisca \& Fleeson, 2004).

Wayne et al. (2007) afirmam que a facilitação trabalho-família pode ocorrer bidirecionalmente, o que significa que o trabalho pode proporcionar ganhos que melhoram o funcionamento do domínio da família (facilitação trabalho-família ou FTF) ou a família pode proporcionar ganhos que melhoram o funcionamento no domínio do trabalho (facilitação famíliatrabalho ou FFT). Os autores afirmam ainda que facilitação trabalho-família pode ser definida como: à medida que um indivíduo engajado em um domínio da vida (seja no trabalho ou na família) oferece ganhos (de desenvolvimento, afeto, capital, eficiência) que contribuem para um melhor funcionamento de outro domínio da vida (seja na família ou no trabalho).

Para Greenhaus e Powell (2006) enriquecimento trabalho-família (ETF) ocorre quando experiências do trabalho melhoram a qualidade de vida na família e enriquecimento famíliatrabalho (EFT) ocorre quando experiências familiares melhoram a qualidade de vida no trabalho. De acordo com Sieber (1974), um dos principais quadros teóricos que parte do pressuposto de que a participação de papéis pode influenciar positivamente o trabalho e a família é a Teoria da Valorização do Papel. Essa teoria pressupõe que a atividade profissional pode influenciar positivamente a família e vice-versa. $\mathrm{O}$ autor baseia-se no princípio de que o desempenho simultâneo de papéis, ou a acumulação desses, facilita o acesso a recursos, que podem ser úteis para o desempenho de outros papéis.

O autor acrescenta que os benefícios do acúmulo de papéis podem superar o estresse e resultar em satisfação e que a participação em múltiplos papéis pode ser estimulante e aumentar o bem-estar dos indivíduos. Conforme Greenhaus e Powell (2006) há três maneiras pelas quais a participação em múltiplos papéis, também denominada de acumulação de papéis, pode produzir resultados positivos para os indivíduos:

$1^{\circ}$ ) experiências do trabalho e experiências da família podem ter efeitos aditivo no bem-estar (indivíduos que participam e estão satisfeitos com os papéis profissional e familiar experimentam 
maior bem-estar do que aqueles que participam apenas de um dos papéis ou que estão insatisfeitos com um ou mais dos seus papéis);

$2^{\circ}$ ) a participação nos papéis trabalho e família podem amortecer a angústia dos indivíduos em um dos papéis;

$3^{\circ}$ ) experiências em um papel podem produzir experiências positivas nos resultados do outro papel. Este mecanismo difere dos dois anteriores porque ele representa uma transferência de experiências positivas de um papel para outro (a participação em alguns papéis cria uma energia que pode ser usada para aprimorar as experiências em outros papéis).

Greenhaus \& Powell (2006) apontam o terceiro mecanismo como o que melhor captura seu conceito de enriquecimento trabalho-família, qual seja: medida em que experiências em um papel melhoram a qualidade de vida em outro. Uma pesquisa desenvolvida por Hill (2007), em uma grande empresa multinacional, foi solicitado aos funcionários que descrevessem as influências positivas de sua vida profissional em sua vida familiar e vice-versa. As influências mais citadas pelos participantes da pesquisa, como componentes importantes da facilitação do trabalho para família (FTF) foram: flexibilidade no local de trabalho, benefícios financeiros e a capacidade de manter compromissos familiares. Relações familiares favoráveis, benefícios psicológicos da família e os aspectos psicológicos de trabalho foram mais frequentemente identificados como componentes importantes da facilitação da família para o trabalho (FFT).

Nessa pesquisa, Hill (2007) utilizou métodos qualitativos para explorar a percepção dos funcionários de como a vida no trabalho é reforçada pelas experiências da vida familiar e como a vida familiar é reforçada pelas experiências da vida no trabalho. Os resultados revelaram aspectos do trabalho remunerado que facilitam e são facilitados por aspectos específicos da vida familiar, bem como aspectos da vida familiar que facilitam, e são facilitados por aspectos específicos do trabalho remunerado. A flexibilidade foi o fator do trabalho mais mencionado como beneficiando a família. Os dados demonstraram que a vida no trabalho e na família são, em muitos aspectos, complementares em vez de competitivas.

Conforme Carlson et al. (2011), estudos anteriores postulam que o enriquecimento trabalhofamília está positivamente relacionado ao desempenho no trabalho e que grande parte desses estudos, baseou-se nas teorias da acumulação do papel e da conservação dos recursos. Ambas as teorias sugerem que os recursos empregados não são fixos ou sujeitos apenas ao esgotamento, mas que podem ser expandidos. Carlson et al. (2011) argumentam, ainda, que a premissa central é de que o investimento de recursos (ex.: energia, tempo) em um domínio pode levar a um aumento de recursos (ex.: habilidades, resiliência) em outro domínio. No seu entendimento, um empregado que aprende estratégias eficazes priorizando a gestão de conflitos no trabalho pode descobrir momentos em que essas mesmas habilidades têm efeito positivo em sua família.

Essa compreensão reforça a afirmação de Sieber (1974) de que há recompensas quando se participa de múltiplas funções. Para o autor, os resultados positivos da acumulação de papéis podem ser classificados em quatro tipos: 1) privilégios de função; 2) estado geral de segurança; 3) recursos para melhoria de status e desempenho de papel; e 4) o enriquecimento da personalidade e gratificação do ego. 


\section{PERCURSO METODOLÓGICO}

Para o alcance dos objetivos propostos neste artigo, adotou-se a pesquisa qualitativa como abordagem de análise pela sua possibilidade de responder a questões particulares, já que se preocupa com uma realidade que não pode ser quantificada devido à subjetividade do seu objeto, ou seja, por envolver significados, motivos, aspirações, crenças, valores e atitudes que não podem ser reduzidos à operacionalização de variáveis (Minayo \& Gomes, 2009). Optou-se pelo uso da metodologia do estudo de caso, pelo fato de seu objeto de estudo encontrar-se inserido no contexto aplicado a uma Instituição de Ensino Superior Pública e pela pesquisa de campo por tratar-se de uma investigação empírica para levantamento de dados primários, realizada in loco onde está ocorrendo o fenômeno.

Participaram como sujeitos da pesquisa 20 servidores ativos ocupantes do cargo de secretário executivo da Instituição. Para a obtenção dos dados foi utilizada a técnica de entrevista por ser considerada fundamental na pesquisa qualitativa e por ter como objeto primário o entendimento dos significados atribuídos pelos entrevistados a questões e situações em contextos que não foram anteriormente estruturados a partir das suposições do pesquisador (Roesch, 2005).

Para a obtenção das informações necessárias ao estudo, optou-se pela entrevista semiestruturada. Após a realização de uma "pré-enquete", desenvolveu-se um roteiro de entrevistas com base nos objetivos da pesquisa e na literatura estudada. Validado o roteiro, as entrevistas foram realizadas nos meses de fevereiro e março de 2012, com duração média de 20 a 30 minutos e gravadas com a autorização dos sujeitos para posterior transcrição e análise. O roteiro tratou das categorias: significado de família e de trabalho, enriquecimento na interação trabalho-família e, implicações do enriquecimento da interação trabalho-família; todas associadas às implicações da relação trabalho-família.

Colhidas as informações, pode-se traçar o perfil dos entrevistados e identificar as respostas necessárias ao alcance dos objetivos da investigação. Para o tratamento e análise dos dados obtidos nas entrevistas, utilizou-se da técnica de análise de conteúdo. A escolha dessa técnica se deu pela sua adequação à interpretação da pesquisa qualitativa, uma vez que compreende o sentido das falas dos sujeitos e permite ao pesquisador fazer inferências sobre qualquer elemento da comunicação.

Conforme Bardin (2011), a análise de conteúdo é um conjunto de técnicas de análise das comunicações que tem como finalidade a obtenção de indicadores (quantitativos ou não) que permitam a inferência de conhecimentos relativos às condições de produção/recepção (variáveis inferidas) das mensagens, por meio de procedimentos sistemáticos e objetivos de descrição do conteúdo dessas mensagens. Nesse sentido, optou-se pela utilização de tal técnica, visto que ela organiza o processo de análise em três fases: pré-análise, exploração do material e tratamento dos resultados.

O processo de análise iniciou-se a partir da transcrição das entrevistas gravadas, gerando um protocolo para cada entrevista. Fizeram-se recortes das partes significativas, gerando protocolos codificados. Para a identificação dos protocolos de entrevista utilizou-se o código Snq, onde "S" representa a palavra Secretário, " $n$ " representa o número correspondente ao secretário entrevistado, e "q" corresponde à letra da questão a qual foi retirada a unidade de registro. Bardin (2011) 
explicita que unidade de registro é a unidade de significação codificada que corresponde ao seguimento de conteúdo considerado como unidade de base. Para a autora, esse tipo de unidade pode ser de natureza e dimensões bastante variadas, no entanto, efetivamente são executados recortes em nível semântico, como o tema.

Dessa forma, optou-se pela utilização do tema como unidade de registro. O tema pode ser entendido como a unidade de significação de um texto analisado conforme critérios relativos ao arcabouço teórico que serve de guia à leitura (Bardin, 2011).

A partir da seleção e agregação dos trechos dos discursos foi-se alimentando as categorias de análise previamente estabelecidas, utilizando-se do critério de categorização semântico para agrupar os temas de mesma significação a um determinado título. Após serem reunidos todos os elementos pertinentes a cada categoria, pôde-se ter uma maior compreensão da percepção dos secretários, confrontá-la com a teoria pesquisada e fazer inferências. Isso possibilitou responder a questão de pesquisa e elaborar o relatório de análises, chegando-se, assim, ao atendimento dos objetivos propostos nesse trabalho.

\section{ANÁLISE E DISCUSSÃO DOS DADOS}

\subsection{O PERFIL DOS SUJEITOS}

Quanto ao perfil sociodemográfico, dos 20 entrevistados, 16 são do gênero feminino, revelando a predominância de mulheres na ocupação do cargo de secretário executivo na Instituição. A idade mínima encontrada foi 25 anos e máxima de 60 anos, predominando a faixa etária de 25 a 35 anos.

Quanto o grau de instrução, sete têm apenas o nível de graduação (pré-requisito mínimo para o ingresso no cargo); 11 encontram-se no nível de especialização, e dois na fase de conclusão do mestrado. Os dados sugerem esse resultado, basicamente, por três motivos: as atribuições do cargo requerem conhecimentos de alto nível e preveem uma formação com múltiplas competências, habilidades e elevado nível intelectual, conforme a Classificação Brasileira de Ocupação -CBO (Brasil, 1977); os sujeitos da pesquisa encontram-se inseridos em uma Instituição de Ensino Superior, formadora de conhecimentos, que oportuniza a qualificação de seus servidores; a progressão funcional resultante do Plano de Carreira dos Cargos Técnico-Administrativos em Educação - PCCTAE, no âmbito das Instituições Federais de Ensino, vinculadas ao Ministério da Educação (Brasil, 2005).

Todos os entrevistados trabalham em regime de $40 \mathrm{~h}$ semanais; 16 têm até quatro anos na Instituição e quatro têm tempo de serviço variando de 27 a 34 anos, portanto o quadro, em sua maioria, é composto por servidores em início de carreira. Quanto ao estado civil, 13 são casados, revelando a prevalência dos casados entre os secretários entrevistados. Com relação ao número de filhos, 13 secretários têm filhos e em sua maioria na fase da infância e adolescência.

O salário dos entrevistados varia de 4 até um pouco mais que 14 salários mínimos. Essa diferença salarial diz respeito aos benefícios adquiridos por direito, aos incentivos à capacitação e qualificação profissional previstos no PCCTAE e as gratificações de função. Quanto à carga horária de trabalho do cônjuge, verifica-se que dos 13 entrevistados casados, apenas um não tem o cônjuge 
trabalhando fora de casa. Os demais apontam seus cônjuges inseridos no mercado de trabalho.

\subsection{AS CATEGORIAS DA ANÁLISE}

Consoante ao posto nos procedimentos metodológicos, foram estabelecidas as seguintes categorias de análise: significado de família e de trabalho, enriquecimento na interação trabalhofamília e, implicações do enriquecimento da interação trabalho-família, as quais serão explicitadas a seguir.

\subsubsection{SIGNIFICADO DE FAMÍLIA E DE TRABALHO}

No intuito de compreender a importância e a prioridade que o trabalho e a família representam para os secretários, buscou-se, inicialmente, identificar qual o significado desses dois domínios para os entrevistados. A partir dos relatos dos secretários, emergiram os seguintes conceitos de família: tudo, base de tudo, alicerce, sustentação, estrutura para a vida. Conforme os secretários, a família representa principalmente: ponto de apoio, força, equilíbrio, direcionamento, princípios, realização de um projeto pessoal, motivação, vida, amor, união, compreensão, paz, alegria. Alguns desses conceitos podem ser evidenciados a partir dos seguintes fragmentos dos relatos dos entrevistados:

"Para mim, família é tudo" (S7a; S14a; S16a; S19a; S20a); "Família é a base de tudo" (S1a; S2a; S3a; S4a; S8a; S10a; S12a; S17a); "Na minha vida é muito importante, sem a minha família... eu não sou ninguém [...] é o meu refúgio, o meu amparo" (S12a); "É [...] razão de vida mesmo" (S13a); "é a base da sua vida e principalmente o que vai guiar todas as suas ações na vida" (S7a); "família [...] é a estrutura que a gente precisa pra desenvolver nossa profissão [...] é o que nos impulsiona, que nos motiva" (S10a).

O trabalho foi conceituado como um meio de satisfação das necessidades humanas, desde as necessidades mais básicas como as de sobrevivência até as mais elevadas como a realização profissional, e autorrealização. Os dados revelaram que os secretários veem o trabalho como uma dimensão relevante na vida humana, porém, não a de maior importância. "Trabalho pra mim é muito importante. Família é mais [...] mas, eu não me vejo sem o meu trabalho, [...] não tem nem essa possibilidade (rindo)" (S10b). O trabalho foi mencionado, ainda, como um complemento, além de fonte de conhecimento e aprendizado e, meio de sentir-se útil e produtivo. "É o complemento da família, é o que eu preciso pra ajudar no sustento da minha casa" (S2b); "o trabalho dignifica o homem, [...] torna o ser produtivo, ele possibilita interação, ele possibilita desenvolvimento [...]" (S1b); "Trabalho, pra mim, é uma realização [...] é uma forma de estar ativo, de estar vivo, atuante" (S15b).

O trabalho e a família apresentaram-se relevantes e essenciais na vida dos entrevistados. No entanto, nessa categoria de análise, a família foi evidenciada como de maior importância e prioridade para os entrevistados. 


\subsubsection{ENRIQUECIMENTO NA INTERAÇÃO TRABALHO-FAMÍLIA}

Buscou-se, nesta categoria, identificar a percepção dos secretários quanto aos ganhos obtidos a partir da interação dos domínios do trabalho e da família. Foi unânime o entendimento de que existem muitos ganhos e que esses, acontecem como um sistema de trocas, como uma via de mão dupla, ou seja, da família para o trabalho e do trabalho para a família. Essa compreensão pode ser explicitada a partir dos seguintes relatos dos secretários: "Cada papel ajuda o outro [...] o que é melhor aí é a troca. [...] essas trocas fazem a gente crescer" (S14o); "Eu acredito que existam ganhos sim, acho que pra ambas as partes" (S17j).

[...] enquanto a família oportuniza a base de sustentação pra você prosseguir com os problemas da vida, inclusive no trabalho. O trabalho oportuniza que você leve pra família um conforto, um aprendizado também de relacionamento, um aprendizado de ouvir, de organizar, de falar, um aprendizado de adequar-se [...] eu acho que é uma troca (S11).

"Eu acho que a troca de experiências. [...] as informações do trabalho [...] vão aumentando nosso aprendizado. [...] uma informação que você adquire no trabalho pode ajudar uma pessoa na família [...]" (S31). "É uma troca, um ajuda o outro. Porque assim, eu ajudo a minha família com o qu'eu ganho no meu trabalho, [...] no trabalho, eu cresço profissionalmente e pessoalmente, vou amadurecendo e isso reflete também na minha casa" (S12j).

[...] a gente desenvolve vários papéis, [...] cada um vai agregando, vai somando valores, habilidades, práticas, experiências. [...] não que esteja separada a vida do trabalho, da vida da família [...] uma coisa vai influenciando a outra como se fosse um círculo vicioso. Você vai crescendo em cada papel que você desenvolve, vai somando. [...] é isso, intercâmbio em todas as áreas onde você atua (S12o).

Essa visão dos secretários encontra apoio em Sieber (1974), quando da expansão ou aumento de recursos defende que a participação em múltiplos papéis pode proporcionar ao indivíduo recursos como o desenvolvimento de novas competências e habilidades e maior apoio social. O que provavelmente não se obteria se estivesse limitado ao desempenho de um único papel. A seguir o entendimento dos entrevistados sobre o enriquecimento do trabalho e o enriquecimento da família.

\subsubsection{ENRIQUECIMENTO DO TRABALHO}

Os ganhos percebidos pelos entrevistados a partir do trabalho são os seguintes:

- Oportunidade de agregar conhecimentos

Para a maioria dos entrevistados, a oportunidade de agregar conhecimentos a partir do trabalho é uma forma de enriquecimento. As falas abaixo evidenciam essa percepção: 
[...] chegava a conta, pagava, arquivava lá o comprovante, e ponto final. Hoje não! Eu já tenho aquele trabalho de colocar numa planilha o que eu ganho, o que eu gasto, onde eu posso gastar, onde é que eu posso postergar, enfim, é realmente um planejamento. [...] (S15m).

[...] a gente aprende também, todo dia a gente tem que lidar com pessoas [...] a todo momento está melhorando a habilidade de lidar com as pessoas, controlando a sua emoção... pensando no que você vai falar. Então isso tudo são habilidades que vem com a prática e isso a gente leva pro nosso dia a dia também (S13m).

Esses depoimentos reforçam a afirmação de Grzywacz e Marks (2000) ao argumentarem que a teoria do enriquecimento de papel propõe que a participação em múltiplos papéis oferece aos sujeitos muitas oportunidades e recursos, os quais podem ser utilizados para promover o crescimento e um melhor funcionamento de um domínio em outros domínios da vida.

\section{- Flexibilidade e apoio no trabalho}

Verificou-se que, quando há flexibilidade no trabalho e apoio por parte da chefia e dos colegas, há uma maior facilitação na interação trabalho-família, bem como um sentimento de acolhimento e satisfação. Os seguintes relatos demonstram isso:

Existe [...] compreensão, [...] quando é preciso, eu fico além da conta e quando eu também preciso, meu gestor libera sem nenhum problema [...] é muito favorável nesse aspecto. [...] Então isso me deixa muito à vontade, muito tranquilo, muito motivado e principalmente muito comprometido com o qu'eu faço (S4g).

Aconteceu [...] no carnaval [...] minha empregada faltou [...] meu marido estava viajando e eu não tinha com quem deixar as minhas filhas, uma tem 11 anos e a outra tem quatro anos, então não podia deixá-las sozinhas. Eu conversei com a chefia e ela compreendeu. Existe isso aqui nesse setor, essa compreensão com [...] esse tipo de situação (S13i).

Os ganhos que se obtêm a partir da flexibilidade e apoio no trabalho, percebidos pelos entrevistados, são tratados em Greenhaus e Powell (2006) ao sugerirem que a flexibilidade no local de trabalho permite ao indivíduo participar mais plenamente da vida familiar.

-Experiências do trabalho

As experiências do trabalho também foram citadas como tendo influência positiva do trabalho para a família. Para os entrevistados essas experiências facilitam suas vidas:

[...] você sempre amadurece muito quando começa a trabalhar, [...] você lida com muitas pessoas. Então, você... ganha, você cresce emocionalmente, você aprende a lidar com os sentimentos que outrora você não tinha [...] você conhece mais pessoas, [...]. E a família ganha com a questão do trabalho, principalmente quando você [...] tem uma estabilidade, [...] sabe que aquilo [...] é certo [...] que você pode dar um bem-estar melhor pra família [...]. Tem muitos pontos positivos [...] a questão da responsabilidade, a questão da integridade [...] (S8j).

[...] quando você começa a assumir muita responsabilidade no trabalho, você se torna também uma pessoa mais responsável, mais responsável na família, mais responsável na 
sua vida pessoal (S11m).

"Um ganho pra mim também são as experiências dos meus dirigentes, dos meus colegas de trabalho, é um olhar de pessoas que me dá uma energia” (S14m).

Acho que você amadurece bastante pra ambos os lados. Tanto no serviço como dentro da família então esse... essa forma de você trabalhar as relações dentro do seu trabalho elas embasam/ dão embasamento pra você também trabalhar dentro da sua/ do seu ambiente familiar. Acho que dá muito amadurecimento (S17m).

[...] quando eu me casei [...] eu mesma fiz todo o meu roteiro de viagem [...] isso decorre da experiência [...] do trabalho [...]. O conhecimento [...] do trabalho, eu levei pro meu lado pessoal [...]. Eu já conhecia alguns hotéis, já conhecia algumas agências que podiam me ajudar na época que casei e que fiz a minha lua-de-mel. [...] Aproveitei o lado profissional pra engajar no lado pessoal e foi maravilhoso ( $\mathrm{S} 9 \mathrm{~m})$.

A percepção apresentada por vários secretários entrevistados acerca dos ganhos que as experiências do trabalho lhes proporcionam remetem as afirmações de Grenhaus e Powell (2006) de que as experiências obtidas em um papel produzem efeitos positivos em outro, visto que a participação em algumas ações cria uma energia que pode ser usada para aprimorar experiências em outras. Esses relatos também encontram sustentação em Sieber (1974) ao sugerir que as várias responsabilidades, oportunidades e o contato com diversas pessoas promovem competências que levam ao auto-conceito do indivíduo.

\section{- Benefícios financeiros}

O salário também aparece nos discursos dos entrevistados como um elemento facilitador da vida familiar. Ele aparece nas falas desses secretários sempre acompanhado de outros elementos que geram enriquecimento. Isso demonstra a percepção dos secretários de que o salário não é o único nem o mais importante elemento do enriquecimento do trabalho.

\footnotetext{
Bom, do meu trabalho pra família [...] a questão financeira melhorou bastante, né, e a questão também do conhecimento [...], informações da Universidade [...], oportunidades [...] que você acaba tomando conhecimento aqui, né, e repassando pros nossos familiares. (S91).
}

É importante o salário (rindo). É importante. "Os proventos são importantes [...] pra que a família possa ir adiante [...]" (S14). "Muita felicidade, bom salário, responsabilidade, [...] estabilidade [...]" (S191). [...] "foi à independência mesmo, a questão de deslanchar assim, de sair de casa" [...] "tomar conta de mim, [...] da minha casa. Eu acho que esse foi o maior ganho" (S11j).

Acerca das facilitações que o salário pode promover para a família, Greenhaus e Powell (2006) afirmam que, entre outros, o dinheiro proveniente do trabalho pode ser utilizado para melhorar a qualidade de vida da família por meio da compra de bens e serviços que torna a vida da família mais fácil ou mais agradável e que a renda familiar total promove estabilidade conjugal.

- Satisfação 
A satisfação emerge nos discursos dos entrevistados como um recurso psicológico que lhes fortalece para o enfrentamento das dificuldades inerentes ao trabalho e a família. Conforme relatos, é gratificante estar trabalhando, sentindo-se útil, poder contribuir para o atendimento de necessidades de outras pessoas, sentir-se reconhecido. A satisfação que se obtém a partir desses elementos do trabalho estimula e motiva o indivíduo para a vida.

[...] preciso trabalhar pra me sentir completa, pra me sentir feliz, sentir qu'eu estou fazendo alguma coisa útil pela sociedade. [...] isso também é uma contribuição social. [...] então... eu acho que a partir do momento que me realiza [...] me traz felicidade, [...] compensações maravilhosas (S13j).

[...] eu acredito que a satisfação, né, de estar em um ambiente bom de se trabalhar, num ambiente onde eu estou me realizando profissionalmente. [...] Então, eu acho que é satisfação de está em uma universidade como esta [...], isso traz muita coisa positiva, né, em relação a profissão, a relacionamento (S91).

[...] eu gosto muito do qu'eu faço como profissional e como mãe. [...] um completa o outro. [...] eu amo ser secretária executiva, Então, [...] é uma coisa que me completa. Hoje me completa as duas coisas (S8o).

Nesses discursos, evidenciam-se os benefícios que a satisfação proveniente do trabalho traz para o indivíduo contribuindo positivamente nessa e em outras esferas da vida. De acordo com Grenhaus \& Powell (2006) indivíduos que acumulam papéis podem compensar falhas em um papel por meio da satisfação em outro papel.

- O trabalho em si

Apesar das dificuldades enfrentadas para conciliar trabalho e família, especialmente em decorrência das atribuições dos secretários executivos e das demandas de atividades pertinentes a esses profissionais, os entrevistados revelam a relevância do trabalho em si e os ganhos provenientes da participação neste domínio da vida.

[...] eu comecei a trabalhar muito cedo [...] então assim, abdicar do trabalho pra ser só dona de casa não... não me caberia, acho qu'eu não seria uma pessoa legal dentro de casa né, nem pra mim, nem pro meu marido, nem pro meu filho. Porque na rua você está convivendo com outras pessoas, você está vendo o mundo, você está tendo acesso a outras informações. Imagine você ficar só dentro de casa! Não! Sem condições. O trabalho realmente traz muitos benefícios, pra mim só ganhos. Apesar das dificuldades, o saldo é mais positivo $(\mathrm{S} 18 \mathrm{j})$.

[...] a formação que a gente tem é uma formação bem generalista [...] me ajudou muito na lição com as minhas filhas. Eu me tornei uma pessoa muito mais paciente, [...] aprendi muito a ouvir, [...] ser proativa. [...] então foi uma coisa qu'eu passei muito pra minha família, pras minhas filhas [...] (S8m).

[...] com a minha profissão [...] eu aprendi a me organizar. Eu já era muito metódica, mas talvez eu não soubesse como colocar isso em prática, então assim eu passei a ser uma pessoa muito mais organizada com minhas coisas, planejar [...] ter horários, cumprir com 
esses horários. [...] e com esse conhecimento que eu adquiri de organização de eventos, [...] toda festa da família agora meu nome (rindo) está no meio. [...] isso acaba ajudando também. (S2m).

O trabalho em si emergiu, nesta pesquisa, como um elemento enriquecedor corroborando com as afirmações de Hill (2007) ao sugerir que a produtividade e os desafios do próprio trabalho influenciam positivamente na vida familiar. Para esse autor, um trabalho desafiador e produtivo também funciona como um recurso que reflete positivamente a vida familiar.

\subsubsection{ENRIQUECIMENTO DA FAMÍLIA}

Foram apontados os seguintes ganhos da família, percebidos pelos entrevistados:

- Valores da família

Os valores da família apareceram nos relatos da maioria dos entrevistados, como um aspecto positivo da família. Como explicitado a seguir, esses valores são transmitidos para o indivíduo e ele os carrega para todas as esferas de sua vida, especialmente para o trabalho. Essa percepção pode ser evidenciada a partir dos seguintes discursos:

[...] meus pais eram pessoas muito responsáveis, honestas, pontuais, gostavam das coisas tudo certinho [...], então você vai tendo o exemplo [...] eu acho que você tendo uma base boa da família de responsabilidade, de honestidade, você traz [...] essas qualidades pro trabalho, né, pra você desenvolver um bom trabalho, com competência e etc. (S3n).

[...] responsabilidade, [...] comprometimento, zelo, carinho com as coisas que você está... utilizando ou interagindo, [...] senso de preservação e cuidado [...] são valores inerentes a relação familiar, mas que seguramente a gente traz pro ambiente de trabalho. E aí vem companheirismo, amizade... respeito, lealdade [...] enfim são esses valores básicos que a gente consegue trazer bem... de forma bastante fácil, clara, do ambiente familiar para o ambiente de trabalho (S4n).

"A questão da honestidade, da justiça e do trabalho são três conceitos que eu aprendi na minha vida com meus pais, [...] são valores que aprendi de família, trouxe pro trabalho e onde eu estou, estou com eles [...]" (S5n).

$\mathrm{O}$ que eu ganhei dos meus pais [...] foi respeito. [...] vergonha [...] eles me ensinaram muito. Minha mãe sempre dizia assim: Minha filha, quem tem vergonha não faz vergonha. Então, nunca faça ninguém passar por constrangimento, por vergonha, por uma grosseria ou alguma coisa que você faça. Isso é uma coisa que eu respeito demais e procuro nunca... assim afrontar ninguém (S6n).

É, meu pai que é uma pessoa simples [...] não estudou, veio do interior, uma dificuldade de vida e tal, mas é uma pessoa muito íntegra, muito correta [...] ele sempre educou as filhas 
[...] com valores [...] que são a base do ser humano [...]. Então, o fato de você ser correto, ser íntegro, ser honesto, né? como eles falam muito [...] "fazer as coisas certas". [...] isso são valores que foram passados da minha família e que eu continuo passando [...] pros meus filhos (S10n).

[...] respeito pelo próximo, companheirismo, saber dialogar com as pessoas, ouvir, paciência que muitas vezes a gente tem que ter em casa e também aqui no trabalho [...] acontece alguma situação de atendimento ao público, a pessoa não tá muito calma e você tem que manter aquela calma né, ter aquela habilidade de negociar com o público externo. Então... é isso (S12n).

Eu acho que a família traz muita responsabilidade... a sua vida muda quando você forma uma família, então tudo que você faz tem que ser com muita responsabilidade, tudo que você pensa, tudo que você vai fazer. Então, você acaba trazendo isso pro trabalho também, você quer desempenhar suas atividades da melhor forma possível, porque você está pensando neles, está pensando em como isso pode afetá-los [...] (S13n).

[...] educação, respeito, confiança, compreensão [...] meus pais me proporcionaram estudar em um colégio de freira [...] da ordem franciscana. Foi muito bom essa parte também espiritual, a fé em Deus. [...] E tudo que a gente adquire em termos de educação, de compreensão, de confiança, de respeito a gente colocando na comunicação no dia a dia, no trabalho e na família [...] ajuda demais. Só ajuda (S14n).

A disciplina. Lá em casa, nós [...] fomos criados nessa política bem disciplinadora, certo? Assim, eu acredito que o fato de ser uma pessoa disciplinada [...] ajuda no serviço porque você acaba se organizando e acaba contaminando quem está a sua volta. [...] isso é uma das características mais relevantes na minha pessoa, levo pra onde eu vou [...] acho que é um valor que eu tenho, que eu adquiri na família e que eu levo pro trabalho [...] (S15n).

Olhe, é a questão assim da boa educação, né. Por exemplo, meu pai sempre me instigava [...] você tem que saber entrar nos lugares, saber sair, falar com as pessoas com sinceridade, olhando nos olhos, sempre pedindo licença, essas coisas, [...] essa aprendizagem que eu tive do meu pai, das boas escolas que ele me colocou pra estudar, veio a contribuir muito, principalmente nessa área de secretariado onde você tem que ter uma boa postura, você tem que ter um bom relacionamento com o seu chefe e com os clientes [...] essa base da educação familiar foi muito importante. [...] você vai aprendendo cada vez mais e vai trazendo pra dentro do seu trabalho esse tipo de relacionamento. Então eu sempre busquei por em prática o que meu pai e a minha mãe, minha família me mostrou desde criança. E, pra mim, até agora deu certo (S9n).

[...] as características da sua vida familiar dependem intrinsecamente do seu perfil, da sua personalidade, dos seus valores, então o que você executa na sua vida familiar de positivo você leva também pro trabalho. Por exemplo, se você é uma pessoa que tem um senso de responsabilidade para com sua família $[. .$.$] naturalmente você vai relacionar que o trabalho$ é quem dá o sustento a sua família, ele tem de ser algo prazeroso porque muita gente depende de você. Então, essa forma de visualizar... o trabalho e a [...] sua personalidade pra essas questões de responsabilidade, de respeito, enfim, esses valores inerentes ao ser humano $[\ldots]$ naturalmente leva $[\ldots .$.$] uma carga positiva para o trabalho. Se você é uma$ 
pessoa compreensiva, uma pessoa tolerante, uma pessoa... compenetrada, uma pessoa comprometida [...] com o bem-estar da sua família, você também vai levar isso pro seu trabalho. E a recíproca também é verdadeira [...] (S41).

Conforme esses relatos, pode-se observar que os valores adquiridos na família trazem contribuições muito positivas para a vida profissional à medida que facilita as relações interpessoais, auxilia no desenvolvimento das atividades, aumenta a relação de confiança, favorece a comunicação, entre outros. Segundo Silva (2007, p. 9) "a motivação, o comportamento dos indivíduos e as suas decisões pessoais são moldadas de acordo com os valores que defendem". Santos (2007, p. 12) complementa ao afirmar "o sentido de vida está forçosamente ligado a fatores do meio, tal como os valores familiares e da comunidade onde os indivíduos cresceram”.

- Experiências da família

As experiências da vida em família são apontadas por alguns dos secretários como um elemento de enriquecimento para sua vida pessoal e profissional. Como aparece nos seguintes discursos, às experiências oportunizadas pela vida familiar agregaram aos entrevistados amadurecimento que lhes foi útil em suas vidas como um todo e em especial no trabalho.

$\mathrm{O}$ que a vida me oportunizou amadurecendo precocemente ou não, eu trouxe para o trabalho [...] tipo assim, eu não me deixo abater tão facilmente [...] já passei por tanta coisa na vida que um trabalho que não esteja da forma que eu gostaria ou no clima que eu gostaria não vai me derrubar ou não vai me abater. [...] Eu vejo o ser humano como o somatório de tudo...ou resultante da sua experiência de vida e de sua formação (S1n).

[...] eu tive uma criação muito independente [...] minha mãe trabalhava de dia e meu pai trabalhava a noite. [...] isso me ajudou muito a ser mais confiante pra lidar com os problemas [...] porque eu não tive essa... essa coisa [...] de ser muito protegida [...] eu aprendi a me virar sozinha muito cedo e sempre tive a questão da liderança muito forte na minha casa. [...] Na minha formação como pessoa isso foi muito forte. [...] eu fui [...] ensinada a trabalhar fora, a ver os valores do trabalho, entendeu? a me virar sozinha. Então, eu acho que me ajudou a ser a profissional que sou hoje. [...] a partir desse conceito de você ter que aprender sozinha, não ter medo das coisas, dos desafios, entendeu? então assim meus pais sempre incentivaram muito a gente nesse sentido. [...] você vai fazer porque você é capaz! Eu acho que foi muito essa parte que me ajudou durante toda a minha vida inclusive na minha profissão. (S8n).

[...] Eu sou solteira, mas é como se fosse casada porque desde que meu pai faleceu que eu [...] trabalho pra ajudar a minha mãe e a manter/ a manter os filhos e isso eu fazia com o maior amor e carinho e faço até hoje. [...] isso é até bom pra mim porque repercute no meu dia a dia no trabalho me dando mais condições de saber desenvolver as atividades tá entendendo, porque é preciso também que a gente tenha uma experiência de como controlar situações [...] e isso [...] facilita muito a minha vida. Trabalhar cedo me deu mais maturidade, tá entendendo? E sei muito bem separar uma coisa de outra. (S20d) ${ }^{\circ}$

[...] eu sou mãe, tenho adolescente e trabalho com pessoas mais jovens do que eu. Então assim, às vezes o conflito que eles estão passando em casa e que desabafam no trabalho é mais ou menos o que eu estou passando também com a minha filha. Então assim, [...] a 
experiência como mãe às vezes ajuda [...] pessoas que estão passando por aquela mesma situação, isso é um ganho [...]. Por eu ser mãe, por ter uma experiência de vida [...] por ter começado minha vida muito jovem eu posso transmitir pr'aquelas pessoas que estão trabalhando comigo. Querendo ou não, no trabalho você se abre, você fala da sua família, você se envolve [...] e acaba passando um pouco da sua vida e recebendo um pouco da vida daquela pessoa. Então, o ganho maior eu acho que é essa troca de experiências (S81).

Essa percepção remete ao entendimento de Grenhaus e Powell (2006) ao argumentarem que as experiências de um papel podem produzir experiências positivas nos resultados de outro papel.

- Relacionamento na família

Os achados da pesquisa apontaram a questão do relacionamento na família como um facilitador da vida no trabalho. De acordo com relatos de alguns dos entrevistados, o tipo de relacionamento que têm os indivíduos na esfera familiar pode influenciar de forma positiva ou negativa na vida profissional. Os seguintes relatos demonstram esse entendimento:

"O que você aprende em casa de relacionamento é aplica no trabalho e vice-versa" (S1m). "[...] meu relacionamento com a minha família é muito bom e isso repercute no meu trabalho" (S12j). Outro sujeito contribuiu para esta compreensão dizendo:

[...] o relacionamento bom, companheiro que eu tenho na minha família me traz atitudes pra eu ter com meus colegas de trabalho. [...] tenho todo o respeito com os colegas homens, com minhas colegas mulheres, tenho todo o cuidado de não dizer palavras que venham chocar, essas coisas. Então, eu acho que esse lado, essa harmonia no meu ambiente familiar traz também pro ambiente de trabalho. [...] (S9o).

Esse entendimento de que uma boa relação em família contribui para o bem-estar do individuo no trabalho também foi evidenciada por Hill (2007) ao identificar que relacionamentos positivos e estáveis com o cônjuge, filhos e familiares tendem a facilitar o desempenho positivo no trabalho.

- Apoio da família

Os dados da pesquisa trazem o apoio da família como um elemento facilitador e essencial para o bom desempenho do indivíduo na vida profissional. Esse apoio funciona como o suporte necessário para a harmonia nas duas esferas. Verifica-se tal entendimento nos seguintes discursos que seguem:

Eu tenho apoio e dou todo apoio a minha esposa [...] a gente consegue compartilhar das dificuldades da vida e dos desafios também [...] ela é meu braço... aliás, meus dois braços. Quanto eu estou aqui trabalhando ela fica em casa dando suporte no lar né, dando a estrutura e me deixando, digamos assim, tranquilo [...] (S4c).

[...] eu casei, [...] não deu certo, separei, fiquei com dois filhos. [...] fui criando esses dois filhos com o apoio da minha própria família [...] meus irmãos cobriram essa falta do [...] pai que tava longe [...]. Eu tenho muito a agradecer aos meus irmãos, ao meu cunhado [...] que são exemplos para os meus filhos. E dentro desse contexto estamos todos bem (S5c).

É bem dividido, mas a questão de cuidar de filho fica um pouco mais comigo, embora eu 
tenha o apoio da minha mãe [...]. Eu deixo na escola quando/ às vezes, quando eu tenho que chegar aqui mais cedo e ele está de folga, ele já deixa né, [...] ele pega, ele [...] participa muito. [...] às vezes eu não posso ir reunião da escola, se ele estiver de folga ele vai. [...] quando ele está em casa participa, então assim isso já ajuda muito [...]. Tem esse apoio e, assim, a gente sabe que é importante um pro outro, principalmente porque tem dia que eu passo mais tempo fora de casa do que ele, no outro dia vai ser ele quem vai passar um dia fora de casa, então assim a gente tenta equilibrar isso, né, pra que não sobrecarregue nem um nem o outro (S2d).

[...] meu marido divide tudo comigo desde as coisas da casa, de cozinhar, como [...] dos filhos ensinando a matéria, pegar na escola, conversar com professores, [...] estar sempre muito presente. [...] se não fosse esse apoio eu não poderia continuar estudando jamais, eu não poderia nunca me dedicar ao trabalho do jeito qu'eu me dedico hoje em dia (S13d).

Olha, enquanto eu não estou em casa ela assume todo o papel [...]. Quando eu estou em casa aí a gente compartilha [...] dividindo as tarefas. [...] por consenso a gente nunca quis ter pessoas em casa ajudando, a não ser uma diarista eventual. [...] a gente partiu do princípio de que pra ter privacidade teria que [...] dar conta da nossa realidade. Então, [...] teve que haver esse pacto de cooperação senão a coisa não funciona (S4d).

O apoio da família, conforme relatado pelos secretários, nessa categoria, funciona não só como um atenuante de conflitos, mas também como um facilitador, promovendo maior tranquilidade para o indivíduo no trabalho. Percebe-se que não se pode ter uma visão unidirecional da relação, mas sim bidirecional. No espaço total da vida as pessoas sofrem pressões em ambas as dimensões, contudo vivem experiências significativas em uma dimensão que as auxilia no processo de aprendizagem e de gerenciamento da outra.

\subsubsection{IMPLICAÇÕES DO ENRIQUECIMENTO DA INTERAÇÃO TRABALHO-FAMÍLIA}

Como consequência do enriquecimento da interação trabalho-família, foram apontadas pelos secretários as seguintes implicações:

\section{- Aumento de conhecimentos e habilidades}

Verificou-se, a partir de algumas entrevistas, o entendimento de que o desempenho concomitante dos papéis do trabalho e da família proporciona ao indivíduo ganhos como aumento de conhecimentos e desenvolvimento de novas habilidades e que os ganhos adquiridos em um papel facilitam o desempenho do outro. Os relatos a seguir expressam esse entendimento:

"Ah! Agrega muita coisa boa! Conhecimentos, [...] no trabalho ou na família é a mesma coisa" (S14j). "A gente desenvolve vários papéis [...] então cada um vai agregando, vai somando valores, habilidades, práticas, experiências" (S12o). "Você amadurece muito [...]. Então você... ganha, você cresce" (S8j).

Essa compreensão corrobora com Hill (2007) ao afirmar que algumas habilidades adquiridas no trabalho beneficiam a vida familiar, já que são transferidas de um domínio para outro maximizando as habilidades dos participantes na gestão da família e vice-versa. 


\section{- Benefícios materiais e psicológicos}

Ganhos materiais, partindo do salário e as melhorias que ele pode proporcionar; benefícios psicológicos como conquistas, satisfação e felicidade também foram apontados como ganhos da interação trabalho-família. Os seguintes relatos explicitam esse entendimento:

"É muito importante pra mim. [...] o meu salário [...] ajuda a sustentar a minha casa, meu esposo, meu filho" (S2b). "Trabalho representa conquista, satisfação profissional e alegria. Eu gosto do que eu faço, eu gosto da minha profissão, pra mim é satisfatório trabalhar nessa área de secretariado" (S9b).

A satisfação é apontada como um benefício psicológico. Aqui ela se apresenta como uma consequência positiva da interação trabalho-família, como um enriquecimento da dupla participação de papéis que oportuniza a realização de objetivos desejados e alimenta o ego. Essa compreensão é explicitada por meio dos seguintes relatos:

"Sem dúvida nenhuma, o grande ganho é a satisfação" (S4j). "Eu acho que é a satisfação. Eu sou muito satisfeita na minha família e sou muito satisfeito no trabalho. E essa minha satisfação faz bem pra mim porque eu consigo [...] me relacionar, eu consigo... andar, consigo amanhecer [...] acordar e dormir. Entendeu?" (S6o).

- Melhoria da qualidade de vida

A melhoria da qualidade de vida surge nos relatos das secretárias S2 e S17 como resultado do enriquecimento do trabalho:

Estando trabalhando eu posso ajudar [...] melhorar a qualidade de vida da minha família, [...] se eu não tivesse trabalhando talvez eu não tivesse condições de ajeitar melhor minha casa, [...] eu não poderia me programar pra uma viagem com minha família, então assim tem ganhos, eu sei que tem ganhos. [...] fora o [...] salário, o trabalho proporciona [...] coisas [...] pra the realizar. [...]. Acho que tem muito mais ganho do que perda. Você perde de estar com sua família, você perde de estar mais tempo com seu filho, mas [...] existe uma recompensa no final de tudo isso (S2j).

“O trabalho [...] é onde eu me realizo profissionalmente, é onde eu... eu mostro tudo aquilo que aprendi, é onde eu aprendo a cada dia, onde eu consigo ter boas relações e tudo isso faz parte da minha qualidade de vida" (S17c).

A compreensão acerca da melhoria da qualidade de vida como enriquecimento da relação trabalho-família, relatada por esses secretários, reforça o entendimento de Greenhaus \& Powell (2006) ao argumentarem que as experiências de qualquer papel geram recursos que podem ser proveitosamente utilizados em outro papel, aumentando assim a qualidade de vida.

- Realização pessoal e profissional

Outra consequência apontada por alguns dos entrevistados, como resultante do enriquecimento da interação trabalho-família, é a realização pessoal e profissional. "A partir do momento que me realiza profissionalmente, porque eu acho que a realização profissional para a maioria das pessoas é uma coisa essencial, traz felicidade também” (S13j); “o ganho [...] que eu considero é minha realização pessoal" (S21).

Verifica-se no relato dos entrevistados que eles reconhecem o enriquecimento (facilitação) 
em sua relação trabalho-família como resultante da participação concomitante desses papéis. Os resultados favorecem uma clara compreensão da importância da família e do trabalho para os secretários; revelam o valor que atribuem a essas duas esferas da vida humana; e evidenciam que o trabalho ganha com as heranças positivas da família e que a família ganha com as heranças positivas do trabalho, favorecendo, assim, a vida do indivíduo nas duas esferas.

\section{CONSIDERAÇÕES FINAIS}

Este trabalho objetivou compreender como a interação trabalho e família pode promover o enriquecimento de papéis de Secretário Executivo. Os significados revelados pelos secretários acerca desses domínios foram essenciais para o entendimento da interação trabalho-família, já que o valor atribuído a essas esferas depende da importância que cada indivíduo dá para sua vida. Apesar de elegerem família como maior prioridade, os secretários percebem família e trabalho como esferas significativamente relevantes e complementares.

Verificou a existência de enriquecimento na interação trabalho-família e a interdependência desses domínios da vida dos secretários, evidenciando a influência mútua das duas esferas, ou seja, o trabalho influenciando a família e a família influenciando o trabalho.

Foi unânime o entendimento de que há muitos ganhos nessa relação, evidenciando a existência do enriquecimento na interação nos dois espaços. A percepção dos secretários acerca do lado positivo dessa interação se assemelha a um sistema de trocas, conhecimentos, habilidades e valores adquiridos com as experiências vivenciadas no trabalho e na família apareceram como recursos que contribuem para a melhoria da vida do secretário, em ambos os domínios.

Como elementos geradores de enriquecimento do trabalho, emergiram: oportunidade de agregar conhecimentos, flexibilidade e apoio no trabalho, experiências do trabalho, benefícios financeiros, satisfação, o trabalho em si e o próprio conflito. A oportunidade de agregar conhecimentos foi o elemento enriquecedor do trabalho citado com maior frequência. Quanto aos elementos geradores de enriquecimento da família, foram revelados: valores da família, experiências da família, relacionamento na família e apoio da família. Os valores da família foram identificados entre os elementos de enriquecimento da família com maior regularidade. $\mathrm{O}$ apoio e a experiência emergiram como elementos de enriquecimento comuns aos dois domínios.

As implicações do enriquecimento da interação trabalho-família mais percebidas pelos entrevistados foram: aumento de conhecimentos e habilidades, benefícios materiais e psicológicos, melhoria da qualidade de vida e realização pessoal e profissional.

Identificadas as influências positivas da interação trabalho-família dos secretários entrevistados, assim como a necessidade e a importância reveladas por esses profissionais de estarem inseridos em um contexto de múltiplos papéis, entende-se que não se deve enfatizar o lado negativo da interação, quando é possível encontrar recursos favoráveis ao enriquecimento dos papéis.

Sendo assim, valorizar o lado positivo da relação buscando equilibrar as várias demandas dos diferentes papéis é relevante. A participação nos papéis familiar e profissional foi revelada pelos secretários como uma dinâmica real, necessária e desafiadora, mas que pode levá-los ao enriquecimento. 
Nesse sentido, sugere-se a realização de pesquisas semelhantes a esta que visem aprofundar os estudos referentes ao enriquecimento na interação trabalho-família, haja vista a carência de estudos voltados para o lado positivo dessa interação.

\section{REFERÊNCIAS}

Bardin, Laurence (2011). Análise de conteúdo. Tradução Luis Antero Reto, Augusto Pinheiro (70a ed.) São Paulo: Almedina Brasil.

Brasil. Casa Civil. Presidência Civil. (2005). Lei n. 11.091, de 12 de janeiro de 2005. Dispõe sobre a estruturação do plano de carreira dos cargos técnico-administrativos em Educação, no âmbito das instituições federais de ensino vinculadas ao Ministério da Educação, e dá outras providências. Brasília, DF. Recuperado em 10 de junho, 2012, de <http://www.medicina.ufmg.br/rh/plano_carreira.pdf>.

. Ministério do Trabalho e Emprego. (1977). Classificação brasileira de ocupações-CBO. Brasília, DF. Recuperado em 5 de julho, 2012 de <http://www.mtecbo.gov.br/cbosite/pages/informacoesGerais.jsf>.

Carlson, D. S. et al. (2011). Work-family enrichment and job performance: a constructive replication of affective events theory. Journal of Occupational Health Psychology, 16(3), 297312.

Edwards, M. E. (2001). Uncertainty and the rise of the work-family dilemma. Journal of Marriage and Family, 63, 183-196.

Federação Nacional das Secretárias e Secretários (1996). Lei e regulamentação: registro profissional. Recuperado em 13 de julho, 2011, de <http://www.fenassec.com.br/b_osecretariado_lei_regulamentacao.html>.

Grzywacz, J. G. \& Marks, N. F. (2000). Reconceptualizing the work-family interface: an ecological perspective on the correlates of positive and negative spillover between work and family. Journal of Occupational Health Psychology, 5(1), 111-126.

Greenhaus J. H. \& Powell, G. N. (2006). When work and family are allies: a theory of work-family enrichment. Academy of Management Review, 31(1),72-92.

Hill, E. J. (2007). Work-family facilitation: expanding theoretical understanding through qualitative exploration. Advances in developing human resources, 9(4) 507-552.

Instituto Brasileiro de Geografia e Estatística (2010). Síntese de indicadores sociais: uma análise das condições de vida da população brasileira. Recuperado 11 de julho, 2011, de <http://www.ibge.gov.br/home/estatistica/populacao/condicaodevida/indicadoresminimos/sinte seindicsociais2010/SIS_2010.pdf>.

Minayo, Maria Cecília de Souza \& Gomes, Suely Ferreira Deslandes Romeu (orgs.). (2009). Pesquisa social: teoria, método e criatividade (28a. ed.). Petrópolis, RJ: Vozes. 
Roesch, S. M. A. (2005). Projeto de estágio do curso de administração. São Paulo: Atlas.

Santos, Gina Maria Gaio (2007). O desenvolvimento de carreira dos académicos: uma análise centrada na relação entre o trabalho e a família. Tese de doutorado em Ciências Empresariais Universidade do Minho, Escola de Economia e Gestão, Portugal, 2007.

Sieber, Sam D. (1974). Toward a theory of role accumulation. American sociological review, 39, 567-578.

Silva, Marisa Matias Carvalho. (2007). Vida profissional e familiar: padrões de conflito $e$ facilitação na gestão de múltiplos papéis. Dissertação de mestrado em Psicologia Social Faculdade de Psicologia e de Ciências da Educação da Universidade do Porto, Porto, Portugal.

Universidade Federal do Rio Grande do Norte (2010). Plano de desenvolvimento institucional: 2010-2019. Natal. Recuperado em 25 de março, 2012, de <http://www.sistemas.ufrn.br/portalufrn/PT/pdi2010a2019/final>.

Wayne, J. H. et al. (2007). Work-family facilitation: a theoretical explanation and model of primary antecedents and consequences. Human Resource Management Review, 17, 63-76.

Wayne, j. H; Musisca, N. \& Fleeson, W. (2004). Considering the role of personality in the workfamily experience: Relationships of the big five to work-family conflict and facilitation. Journal of Vocational Behavior, 64,108-130. 